\title{
Wideband Miniaturized Metamaterial Absorber Covering L-Frequency Range
}

\author{
Guo Wen ZHANG, Jun GAO, Xiangyu CAO, Si Jia LI, Huan Huan YANG \\ Information and Navigation College, Air Force Engineering University, Fenghao Road 1st Xi'an 710077, China \\ 849325138@qq.com,gjgj9694@163.com, xiangyucaokdy@163.com,1sj051@126.com,jianye8901@126.com
}

Submitted September 22, 2018 / Accepted December 7, 2018

\begin{abstract}
Using a metallic incurved structure, a wideband miniaturized metamaterial absorber (MMA) covering L-frequency range (1-2 GHz) is proposed in this paper. Simulated results show that the bandwidth of the MMA with absorptivity more than $90 \%$ is $1-2.74 \mathrm{GHz}$, and its relative bandwidth is over 93\%. The size of the unit cell is miniaturized to $20 \times 20 \mathrm{~mm}^{2}$, and the profile is only $0.078 \lambda$ (at the lower frequency of $1 \mathrm{GHz}$ ). Both simulated and experimental results show that high absorptivity for TE and TM polarization over a certain range of incident angles can be gained. By analyzing the effective impedance and the current distribution, the mechanism of the proposed MMA to attain broadband absorption is analyzed. The proposed MMA has a good application on UHF-RFID systems and $4 G$ communications.
\end{abstract}

\section{Keywords}

Miniaturized metamaterial absorber, wideband, L-frequency

\section{Introduction}

Metamaterial absorber (MA) is a kind of structural absorber which consists of a periodic metal structure and dielectric substrate. Compared with the traditional absorber materials, MAs have many advantages, such as thin thickness, light weight, and wide frequency band, which have vitally potential application on radio frequency stealth. In 2008, Landy proposed a perfect metamaterial absorber [1] based on the electromagnetic coupling characteristics of metamaterials. Then, many researchers have done a lot of research in designing MAs with good absorption properties, such as broadband absorption [2-6], multiband [7-9] and polarization insensitivity [10-13]. However, limited to large cell size and narrow bandwidth in the L-frequency range, the MAs will be difficult to be used in practical applications. Thus, MAs are urgently necessary with broadband absorption and small size.

By using some bending shapes [14], [15] or using multilayer technique, periodic structures can be well miniaturized. Increasing the number of resonance points [16],
[17], using multilayer structure [18], and lumped elements [19], [20] are all effective ways to broaden the absorption bandwidth of MA. Small cell size and low-frequency absorption bandwidth generally always could not be taken care of simultaneously. Therefore, MAs in the low-frequency range with both small size and broadband absorption are still challenging, in consideration of these factors.

In this paper, a miniaturized MA (MMA) working in low-frequency range with wide band absorption has been designed and fabricated. The MMA unit cell is well miniaturized to be only $20 \times 20 \mathrm{~mm}^{2}$ by using an incurved structure. Moreover, the MMA has a large absorption bandwidth of 1-2.74 GHz, covering L-frequency range with absorptivity more than $90 \%$. Compared to other structures mentioned above, the MMA has only one closed loop, which can achieve wideband absorption and high miniaturization degree simultaneously. Simulation results show that two key parameters related to the strength of mutual coupling between different parts can influence the positions of the absorption peaks. Then effective impedance and the surface current distribution are combined to explain the electromagnetic coupling and broadband absorption. Finally, the experimental results are given to validate the good performance of the MMA.

\section{Design Principles}

The unit cell of the proposed MMA consists of three layers. The top layer is a simple combination of metallic incurved structure and lumped resistors. The material of dielectric substrate is FR4 with relative permittivity of 4.4 and tangent loss of 0.02 . The middle layer is air. The bottom layer is a full metallic plate, and the conductivity of the metal is $5.8 \times 10^{7} \mathrm{~S} / \mathrm{m}$. The profile of the substrate is only $0.078 \lambda$ (at the low frequency of $1 \mathrm{GHz}$ ). The front view of the basic unit cell of the proposed ultrawide band MMA is presented in Fig. 1(a), and the side view is presented in Fig. 1(b).

The commercial software Ansoft HFSS14.0 based on the finite element method was used for simulation, and the optimized parameters are shown in Tab. 1. In the process of simulation, the value of resistance was set as $160 \Omega$. 


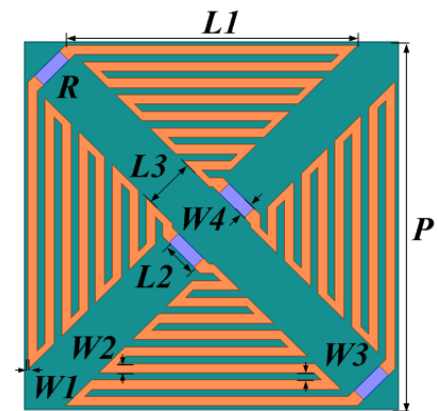

(a)

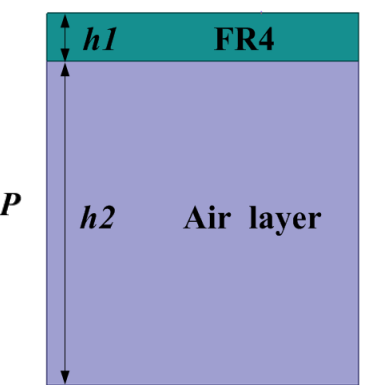

(b)
Fig. 1. The proposed MMA unit cell. (a) Front view. (b) Side view.

\begin{tabular}{|c|c|c|c|c|c|c|c|c|c|c|}
\hline Parameter & $h_{1}$ & $h_{2}$ & $P$ & $L_{1}$ & $L_{2}$ & $L_{3}$ & $W_{1}$ & $W_{2}$ & $W_{3}$ & $W_{4}$ \\
\hline Size $(\mathrm{mm})$ & 3 & 20 & 20 & 10.8 & 1.9 & 6.2 & 0.2 & 0.5 & 0.1 & 0.7 \\
\hline
\end{tabular}

Tab. 1. Dimensions of the unit cell of the MMA.

\section{Simulation and Discussion}

\subsection{Absorption Mechanism Analysis}

Transmission $T(\omega)$ and reflection $R(\omega)$ are obtained from the frequency-dependent S-parameter $S_{11}(\omega)$ and $S_{21}(\omega)$, that is, $T(\omega)=\left|S_{21}(\omega)\right|^{2}$ and $R(\omega)=\left|S_{11}(\omega)\right|^{2}$. The absorption is calculated as:

$$
A(\omega)=1-T(\omega)-R(\omega) .
$$

Since the ground is metal, $S_{21}(\omega)$ is nearly zero in the entire operation band. Therefore, $T(\omega)=0$, further the absorption is calculated as:

$$
A(\omega)=1-R(\omega) .
$$

The absorptivity of MMA was obtained by simulation as shown in Fig. 2. It can be seen that the absorption bandwidth (more than 90\%) is from 1 to $2.74 \mathrm{GHz}$, with a calculated relative bandwidth of $93 \%$. The MMA has high absorption under TE and TM polarization.

The absorber must have the characteristics of impedance matching and loss. Under the plane wave of vertical incidence, the surface reflection coefficient of MMA is as follows:

$$
R=\frac{Z_{\text {eff }}(\omega)-\eta_{0}}{Z_{\text {eff }}(\omega)+\eta_{0}}
$$

$\eta_{0}$ stands for free space wave impedance, which is about $377 \Omega . Z_{\mathrm{eff}}(\omega)$ is the effective impedance of MMA unit. According to the effective medium theory [21], [22], for the absorber with thickness of $H$, the real part of impedance should be satisfied $\operatorname{Re}\left(Z_{\text {eff }}\right)>0$, so the effective impedance of it can be expressed as follows:

$$
Z_{\text {eff }}(\omega)=\sqrt{\frac{\left(1+S_{11}(\omega)\right)^{2}-S_{21}(\omega)^{2}}{\left(1-S_{11}(\omega)\right)^{2}-S_{21}(\omega)^{2}}} .
$$

Put equation (3) into (2) and get (5)

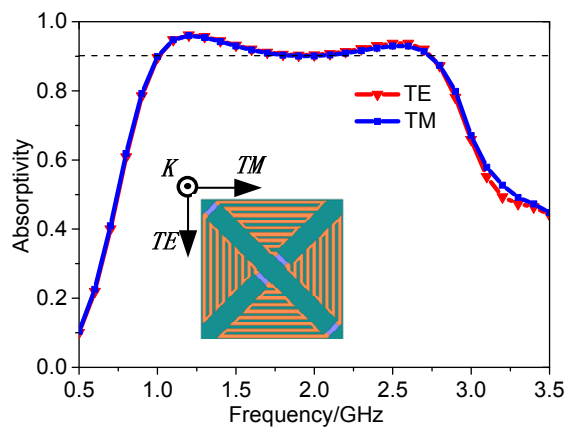

Fig. 2. The MMA's absorptivity under different polarization.

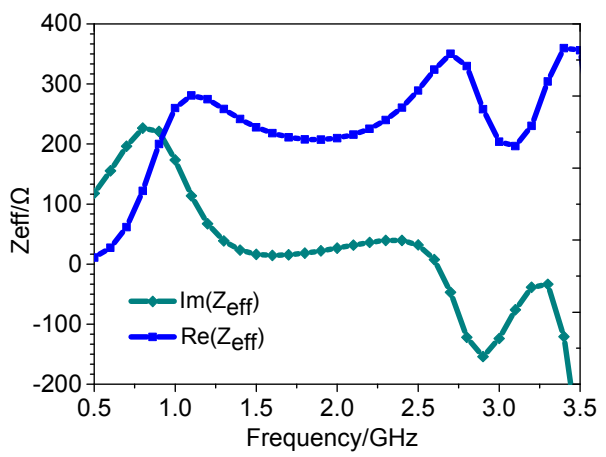

Fig. 3. Effective impedance.

$$
A=\frac{2 \eta_{0}}{\operatorname{Re}\left(Z_{\text {eff }}(\omega)\right)+\mathrm{j} \operatorname{Im}\left(Z_{\text {eff }}(\omega)\right)+\eta_{0}} .
$$

As shown in Fig. 3, in the working frequency range, the real part of impedance approximates $377 \Omega$ and imaginary part is close to zero. According to (5), absorption is close to 1 . It indicates that the MMA has a good impedance matching with free space. The base metal plate of MMA ensures the transmissivity is zero, so the incident wave can only be absorbed by MMA.

In order to analyze the absorbing mechanism of MMA, the MMA's absorptivity with different resistance values was simulated as shown in Fig. 4 . When the resistance was not loaded, the absorption rate was less than 0.07 in the working frequency range. After loading the resistance, the impedance matched well, and the MMA's absorptivity was improved obviously. Figure 4 shows that with the increase of resistance, the center frequency absorption rates increase gradually, but the lower frequency part of the absorption rates decreases. Comprehensively considering absorption rates and absorbing bandwidth, we choose the resistance value of $160 \Omega$ which makes its best absorption property. There are two absorption peaks at $f_{1}=1.2 \mathrm{GHz}, f_{2}=2.6 \mathrm{GHz}$, with absorptivity of $96.3 \%$ and $93.2 \%$.

The cell of the MMA is a compact structure based on a long incurved loop. The total path of the current flowing through the incurved loop can influence the position of the lower resonance point $\left(f_{1}\right)$. Then, the resistors stop the flow of current, thus the path is divided into several shorter paths, which can bring higher resonance point $\left(f_{2}\right)$. Moreover, compactness of the structure can promote electromag- 


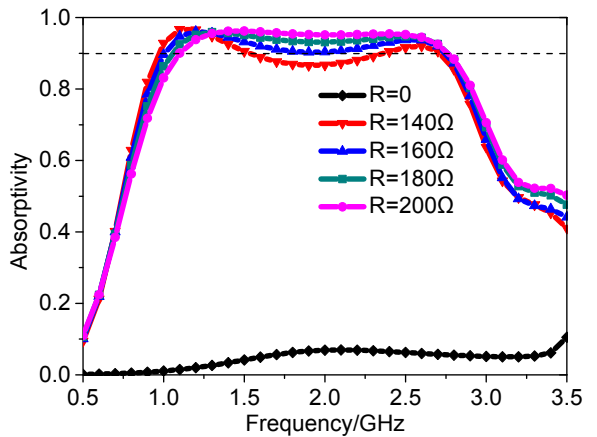

Fig. 4. The MMA's absorptivity under different resistance values.

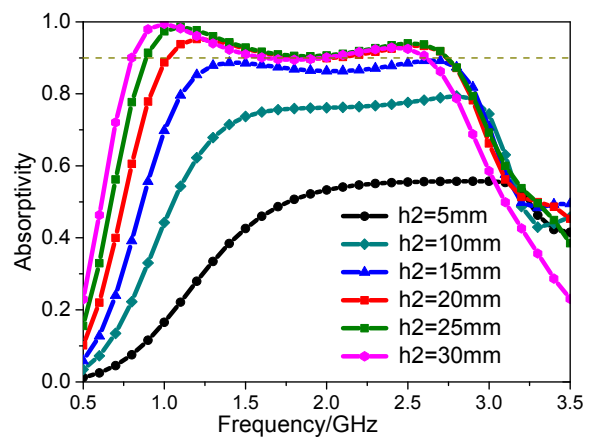

Fig. 5. The curve of absorption with the value of $h_{2}$.

netic coupling between different parts, which may influence the positions of the absorption peaks, further facilitating a broad band united with several narrow bands.

The purpose of the air gap is to reduce the resonant frequency and expand the working bandwidth. Figure 5 shows the curve of absorption changing with the height of air gap $h_{2}$. It can be seen that when $h_{2}$ is less than $20 \mathrm{~mm}$, MMA's absorption increases significantly with the increase of $h_{2}$, and the working frequency band is shifted to the low frequency. When $h_{2}$ is greater than $20 \mathrm{~mm}$, with the increase of $h_{2}$, MMA's absorption is almost constant, and the working frequency band is slightly shifted to the low frequency. Considering the working bandwidth and profile thickness, we chose $h_{2}=20 \mathrm{~mm}$.

Here, interval $L_{3}$ and $W_{2}$ width, which may be two key parameters related to the mutual coupling [16] between different parts of the cell, are studied to examine their effects on absorption. Figures 6(a) and (b) show the absorptions with the size of $W_{2}$ changed from 0.3 to $0.5 \mathrm{~mm}$ and the size of $L_{3}$ changed from 5.4 to $6.2 \mathrm{~mm}$, respectively. Further changing these two parameters will make the structure become relatively compact, which is also limited to fabrication technique.

It is obviously seen from Fig. 6(a) that the second absorption peak drifts to higher frequency, and the absorption rate drops to a value less than $90 \%$ around $2.6 \mathrm{GHz}$ when changing parameter $W_{2}$ from 0.5 to $0.3 \mathrm{~mm}$. Figure 6(b) shows that the absorption curves have a similar trend with the former curves when changing parameter $L_{3}$ from 5.4 to $6.2 \mathrm{~mm}$. However, unlike the former curves, the absorption peak increases to higher frequency when changing parameter

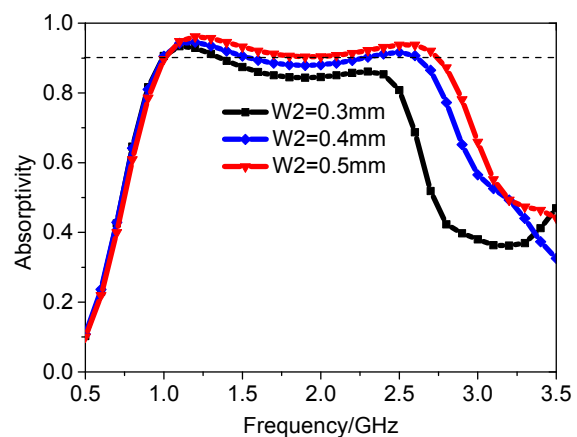

(a)

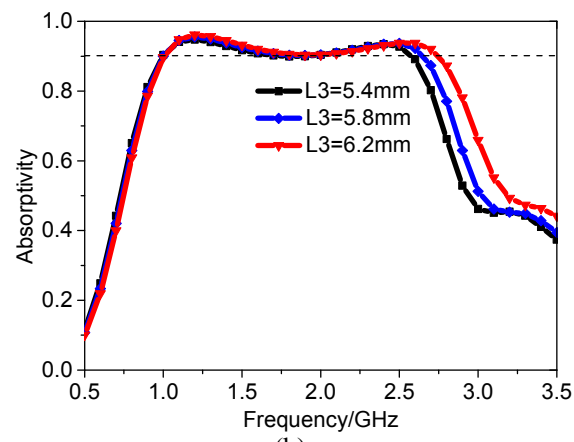

(b)

Fig. 6. Simulated absorptivity of the MMA with the value of one parameter changed while the values of others unchanged. (a) $W_{2}$, (b) $L_{3}$.

$L_{3}$ from 5.4 to $6.2 \mathrm{~mm}$. The above absorption changes and frequency shifts can be ascribed to variation of current path when parameter $W_{2}$ or $L_{3}$ is changed. Detailed explanation of these phenomena will be shown in the following parts combined with surface current distribution.

The MMA is further studied under oblique angle of incidence for both TE and TM polarization as shown in Fig. 7. For TE polarization as shown in Fig. 7(a), it can be seen that the absorption rate remains high over the range of $1-2.74 \mathrm{GHz}$ with incident angle increasing from $0^{\circ}$ to $60^{\circ}$. For TM polarization as shown in Fig. 7(b), the absorption curves have a similar trend with the curves for TE polarization. Although, with incident angle increasing to $60^{\circ}$, the absorption property deteriorates sharply, the absorption rate is still higher than 0.6. The degradation degree of absorbing in TE and TM polarization for oblique incidence depends on amplitude of the incident components (electric component and magnetic component) to incident angle [17].

The comparison between the MMA in this paper and the different MMA currently working in the low frequency band is shown in Tab. 2. Compared with MMA in literature [11], the working bandwidth of MMA in this paper is wider. The working bandwidth level of MMA in literature [12] is similar to that in this paper, but the MMA profile height in this paper is relatively lower. In literature [19], the top layer of MMA is loaded with eight lumped resistors, while the top layer of MMA in this paper is only loaded with four lumped resistors to achieve better wave absorption effect and reduce the processing cost and complexity. In general, MMA in this paper has advantages in relative bandwidth and cell size. 


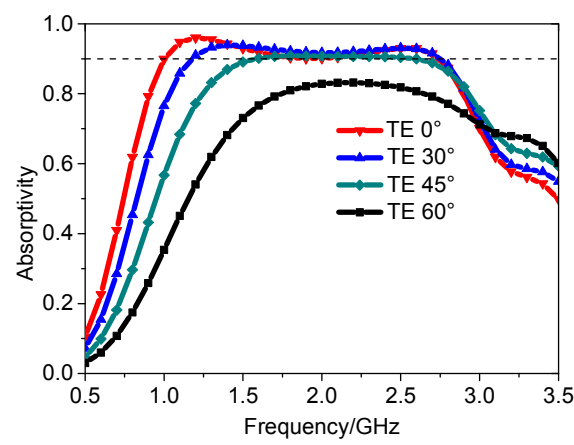

(a)

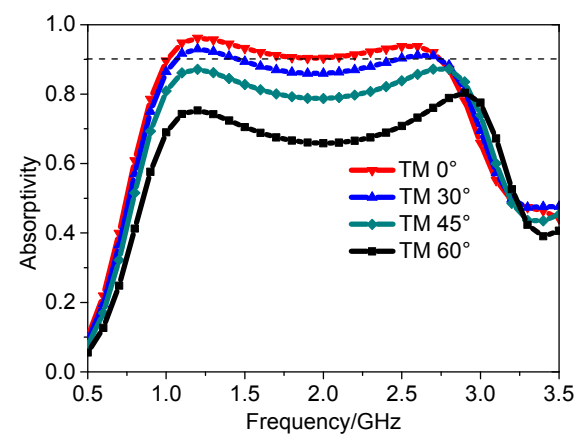

(b)

Fig. 7. Simulated absorptivity of the MMA at four incident angles for: (a)TE polarization, (b)TM polarization.

\begin{tabular}{|c|c|c|c|c|}
\hline ID & $\begin{array}{c}\text { Frequency } \\
\text { range } \\
(\mathrm{GHz})\end{array}$ & $\begin{array}{c}\text { Relative } \\
\text { bandwidth } \\
(\%)\end{array}$ & $\begin{array}{c}\text { Profile } \\
\text { electrical } \\
\text { size }(\lambda)\end{array}$ & $\begin{array}{c}\text { Unit } \\
\text { electrical } \\
\text { size }(\lambda)\end{array}$ \\
\hline$[11]$ & $0.86-0.96$ & 11 & 0.061 & 0.057 \\
\hline$[12]$ & $0.80-2.70$ & 108 & 0.085 & 0.053 \\
\hline$[19]$ & $1.35-3.50$ & 88 & 0.097 & 0.090 \\
\hline This paper & $1.0-2.74$ & 93 & 0.078 & 0.067 \\
\hline
\end{tabular}

Tab. 2. Comparison between different MMA.

\subsection{Surface Current Analysis}

The current distribution on top surface of the MMA is shown in Fig. 8. It is observed that the surface current presents obviously different distributions at different frequencies. Combined with the current distributions, we have divided the top surface into two zones (zone 1 and zone 2). It can be intuitive to find that the lengths of current path in zone 1 and zone 2 at the two resonant frequencies are approximately equal to their corresponding dielectric wavelengths.

The resonant mode at the frequency $f_{1}$ is caused by the current path both in zone 1 and zone 2, as shown in Fig. 8(a). By observing the animation of the current distribution, we also find that the current paths in zone 1 and zone 2 are changed synchronously, indicating a loose mutual EM coupling between zone 1 and zone 2 at this mode.

The resonant mode at the frequency $f_{2}$ is mainly caused by the current path in zone 1, as shown in Fig. 8(b). When animating the current distribution, we find that the

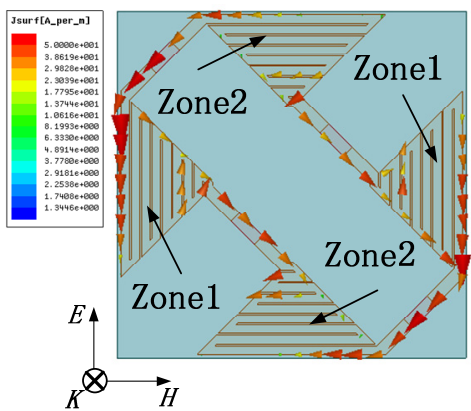

(a)

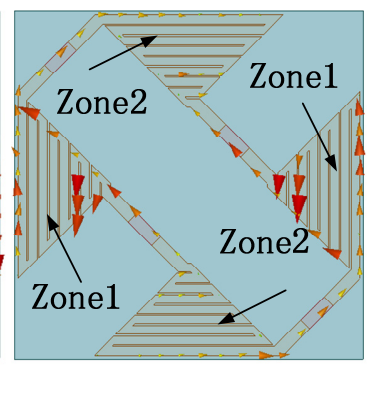

(b)
Fig. 8. The current path of MMA: (a) $1.2 \mathrm{GHz}$, (b) $2.6 \mathrm{GHz}$.

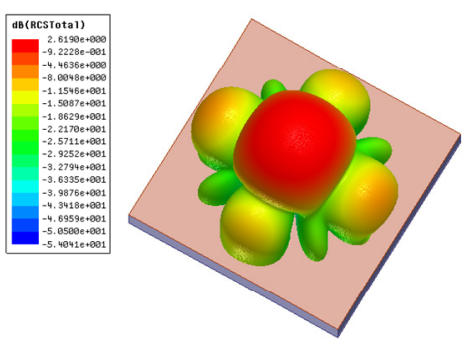

(a)

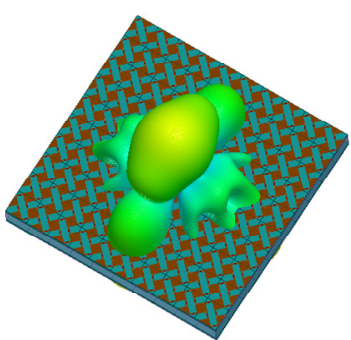

(b)
Fig. 9. Electromagnetic field distribution $(f=2.6 \mathrm{GHz})$ : (a) Metal plate. (b) MMA.

current paths in zone 1 and zone 2 alternately decrease and increase (the total current path remains almost constant), indicating a strong mutual coupling at this mode. The benign coupling helps to extend the total current path in zone 1 and zone 2. Combined with Fig. 6(a), when increasing the width $W_{2}$, the mutual coupling will become loose, and then the current paths get shorter. Thus, the second absorption peak will shift to higher frequency. Briefly, it provides an idea for adjusting the positions of multiple resonate frequencies by utilizing coupling effect on current path to attain broadband absorption.

The radar cross section of MMA and metal plates of the same size at $2.6 \mathrm{GHz}$ is shown in Fig. 9. It can be clearly seen that the scattering field of MMA is much smaller than that of metal plates, which also more intuitively verifies the good absorption property of MMA.

\section{Fabrication and Measurement}

The proposed MMA is fabricated with total dimension of $20 \times 20$ unit cells. Figure 10 shows the MMA sample and the experimental environment, in which two double ridged horn antennas and a vector network analyzer (Agilent N5230C over frequencies from $300 \mathrm{kHz}$ to $20 \mathrm{GHz}$ ) are used. The MMA sample is fixed on a bracket in a microwave anechoic chamber. The transmitting and receiving antennas are placed on either front side of the center of the MMA sample to measure the reflection. The disparity of the reflection between the MMA sample and a copper plate with the same dimension can be seen as the absorptivity.

Figure 11 shows the measured absorption curves for TE and TM polarization, with the simulated curves given 


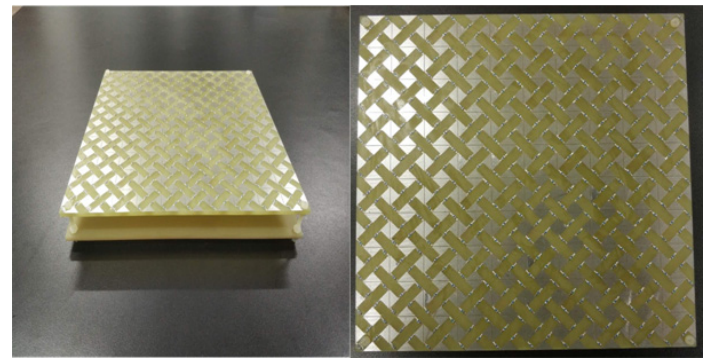

(a)

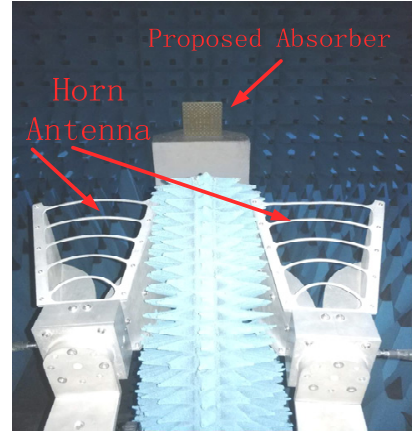

(b)

Fig. 10. (a) Array of MMA. (b) Test environment.

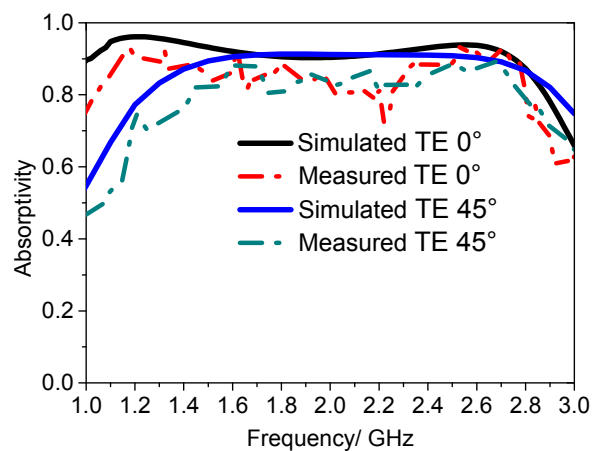

(a)

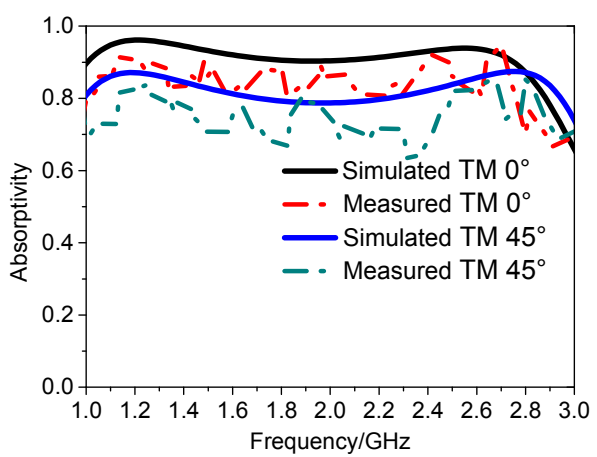

(b)

Fig. 11. Simulation and measurement result of absorption at different angles. (a) TE polarization. (b) TM polarization.

again for comparison. The experimental results show good agreement with the simulated results for TE and TM polarization at $\theta=0^{\circ}$. However, the experimental results at $\theta=45^{\circ}$ are somewhat in large disagreement with the simulations, which is mainly caused by the direct transmitting/receiving $(T / R)$ between the antennas because of their relatively wide beam width. The direct $T / R$ will be more when increasing the incident angle. Furthermore, as the beam width of two double ridged horn antennas in the H-plane is slightly wider than that in the E-plane, the direct $T / R$ under $T E$ mode can be more than that under TM mode. Hence, there are relatively larger errors in the measurement of absorption for TE polarization at $\theta=45^{\circ}$. The measured errors may also be caused by some other factors, such as the inherent tolerances of the MMA sample in the fabrication process and the effect of edge diffraction of the MMA sample.

\section{Conclusion}

In this paper, a wideband miniaturized metamaterial absorber in the L-frequency range is studied. The cell size is reduced to only $20 \times 20 \mathrm{~mm}^{2}$ by using an incurved structure. Simulated results show a wide absorption band (1-2.74 GHz) with absorptivity more than 90\%. By simulating the surface current distribution, we find the benign coupling from the compact structure can affect the shift of the absorption peaks to attain broadband absorption. Furthermore, experimental results also show a good absorption property within an incident angle of $45^{\circ}$. Moreover, such a design may have potential value as absorbing elements to be used in low frequency applications.

\section{Acknowledgments}

This work is supported by the National Natural Science Foundation of China (No. 61701523, No. 61471389, and No. 61671464). Authors also thank reviewers for their valuable comments.

\section{References}

[1] LANDY, N. I., SAJUYIGBE, S., MOCK, J. J., et al. Perfect metamaterial absorber. Physical Review Letters, 2008, vol. 100, article no. 207402. DOI: 10.1103/PhysRevLett.100.207402

[2] HAN, Y., CHE, W. Q. Low-profile broadband absorbers based on capacitive surfaces. IEEE Antennas and Wireless Propagation Letters 2017, vol. 16, no. 8 p. 74-78. DOI: 10.1109/LAWP.2016.2556753

[3] DING, F., CUI, Y. X., GE, X. C., et al. Ultra-broadband microwave metamaterial absorber. Applied Physics Letters 2017, vol. 100 , no. 10, p. 1-4. DOI: 10.1063/1.3692178

[4] ZHANG, C., CHENG, Q., YANG, J., et al. Broadband metamaterial for optical transparency and microwave absorption. Applied Physics Letters, 2017, vol. 100, no. 10, p. 1-5. DOI: 10.1063/1.4979543

[5] FAN, Y., ZHANG, H. C., YIN, J. Y., et al. An active wideband and wide-angle electromagnetic absorber at microwave frequencies. IEEE Antennas and Wireless Propagation Letters, 2016, vol. 15, p. 1913-1916. DOI: 10.1109/LAWP.2016.2544399

[6] KUNDU, D., MOHAN, A., CHAKRABARTY, A. Single layer wideband microwave absorber using array of crossed dipoles. IEEE Antennas and Wireless Propagation Letters, 2016, vol. 15, p. 1589-1592. DOI: 10.1109/LAWP.2016.2517663 
[7] LI, H., YUAN, L. H., ZHOU, B., et al. Ultrathin multiband gigahertz metamaterial absorbers. Journal of Applied Physics, 2011, vol. 110, no. 2, p. 1-8. DOI: 10.1063/1.3608246

[8] SHANG, S., YANG, S. Z., TAO, L., et al. Ultrathin triple-band polarization-insensitive wide-angle compact metamaterial absorber AIP Advances, 2016, vol. 6, no. 7, p. 1-8. DOI: $10.1063 / 1.4958660$

[9] ZHONG, H. T., YANG, X. X., TAN, C., et al. Triple-band polarization-insensitive and wide-angle metamaterial array for electromagnetic energy harvesting. Applied Physics Letters, 2016, vol. 109 , no. 6, p. 1-4. DOI: 10.1063/1.4973282

[10] YANG, W. C., WANG, H., CHE, W. Q., et al. A wideband and high-gain edge-fed patch antenna and array using artificial magnetic conductor structures. IEEE Antennas and Wireless Propagation Letters, 2013, vol. 12, p. 769-772. DOI: 10.1109/LAWP.2013.2270943

[11] ZUO, W., YANG, Y., HE, X., et al. A miniaturized metamaterial absorber for ultrahigh-frequency RFID system. IEEE Antennas and Wireless Propagation Letters, 2017, vol. 10, p. 329-332. DOI: 10.1109/LAWP.2016.2574885

[12] ZUO, W., YANG, Y., HE, X., et al. An ultrawideband miniaturized metamaterial absorber in the ultrahigh-frequency range. IEEE Antennas and Wireless Propagation Letters, 2017, vol. 16, p. 928-931. DOI: 10.1109/LAWP.2016.2614703

[13] SIM, D., KWON, J., CHONG, Y. J., PARK, S. Design of electromagnetic wave absorber using periodic structure and method to broaden its bandwidth based on effective circuit based analysis. IET Microwaves, Antennas \& Propagation, 2015, vol. 9, no. 2 , p. $142-150$. DOI: 10.1049 /iet-map.2013.0487

[14] CHEN, Q., BAI, J., CHEN, L., et al. A miniaturized absorptive frequency selective surface. IEEE Antennas and Wireless Propagation Letters, 2015, vol. 14, p. 80-83. DOI: 10.1109/LAWP.2014.2355252

[15] LI, H., YANG, C., CAO, Q., et al. An ultrathin band-pass frequency selective surface with miniaturized element. IEEE Antennas and Wireless Propagation Letters, 2016, vol. 8, p. 341-344. DOI: 10.1109/LAWP.2016.2575919

[16] LEE, J., LIM, S. Bandwidth-enhanced and polarization-insensitive metamaterial absorber using double resonance. Electronics Letters, 2011, vol. 47, no. 1, p. 8-9. DOI: 10.1049/el.2010.2770

[17] LIU, S., CHEN, H. B., CUI, T. J. A broadband terahertz absorber using multi-layer stacked bars. Applied Physics Letters, 2015, vol. 106, no. 15. p. 1-5. DOI: 10.1063/1.4918289

[18] YOO, M., KIM, H. K., LIM, S. Angular- and polarization-insensitive metamaterial absorber using subwavelength unit cell in multilayer technology. IEEE Antennas and Wireless Propagation Letters, 2016, vol. 15, p. 414-417. DOI: 10.1109/LAWP.2015.2448720

[19] BANADAKI, M. D., HEIDARI, A. A., NAKHKASH, M. A metamaterial absorber with a new compact unit cell. IEEE Antennas and Wireless Propagation Letters, 2018 vol. 17, no. 2, p. 205-208. DOI: 10.1109/LAWP.2017.2780231

[20] LI, S. J., WU, P. J., XU, H. X., et al. Ultra-wideband and polarization-insensitive perfect absorber using multilayer metematerials, lumped resistors, and strong coupling effects. Nanoscale Research Letters, 2018, vol. 13, p. 1-13. DOI: 10.1186/s11671-018-2810-0

[21] SMITH, D. R., VIER, D. C., KOSCHNY, T., et al. Electromagnetic parameter retrieval from inhomogeneous metamaterials. Physical Review E, 2005, vol. 71, no. 3, p. 1-11. DOI: 10.1103/PhysRevE.71.036617

[22] SZABO, Z., PARK, G.-H., HEDGE, R., et al. A unique extraction of metamaterial parameters based on Kramers-Kronig relationship. IEEE Transactions on Microwave Theory and Techniques, 2010, vol. 58, no. 10, p. 2646-2653. DOI: 10.1109/TMTT.2010.2065310

\section{About the Authors ...}

GuoWen ZHANG was born in ChongQing Municipality, in 1995. He received the B. S. degree from the Information and Navigation College, Air Force Engineering University in 2017. He is now a graduate student. His research interest is in electromagnetic metamaterial. He has been working with the EMC Lab, since 2017. His research activity has been focused in the broadband and fractal artificial magnetic conductor, coding metamaterial and its application for $\mathrm{RCS}$ reduction of antennas.

Jun GAO received the B.Sc. and M.A.Sc. degrees from the Air Force Missile Institute in 1984 and 1987, respectively. He joined the Air Force Missile Institute in 1987 as an assistant teacher. He became an associate professor in 2000 . $\mathrm{He}$ is currently a professor of the Information and Navigation College, Air Force Engineering University of CPLA. He has authored and coauthored more than 100 technical journal articles and conference papers, and holds one China soft patent. His research interests include smart antennas, electromagnetic metamaterial and their antenna applications.

Xiangyu CAO received the B.Sc. and M.A.Sc. degrees from the Air Force Missile Institute in 1986 and 1989, respectively. She joined the Air Force Missile Institute in 1989 as an assistant teacher. She became an associate professor in 1996. She received Ph.D. degree in the Missile Institute, Air Force Engineering University in 1999. From 1999 to 2002, she was engaged in postdoctoral re-search in Xidian University, China. She was a Senior Re-search Associate in the Dept. of Electronic Engineering, City University of Hong Kong from June 2002 to Dec 2003. She is currently a professor of the Information and Navigation College, Air Force Engineering University of CPLA. She is the IEEE senior member from 2008. She has authored and coauthored more than 200 technical journal articles and conference papers, and holds one China soft patent. She is the coauthor of two books entitled Electromagnetic Field and Electromagnetic Wave, and Microwave Technology and Antenna published in 2007 and 2008, respectively. Her research interests include smart antennas, electromagnetic metamaterial and their antenna applications, and electromagnetic compatibility. She is a reviewer of Applied Physics Letter, Journal of Applied Physics, IEEE Transactions on Antennas and Propagation, and IEEE Antennas and Wireless Propagation Letter.

Si-Jia LI was born in Xi' an, Shaanxi province, P.R. China in 1987. He received Ph.D. degree in Electronic Science and Technology at the Information and Navigation College, Air Force Engineering University in 2015. He was a lecturer in the Air Force Engineering University from 2015 to 2017. Now he is the Associate Professor from 2017 and the master instructor from 2018. His research activity has been focused in the broadband perfect metamaterial absorber and its application for RCS reduction of antennas. He is a reviewer of the Applied Physics Letter, Journal of Applied Physics, IEEE Transactions on Microwave Theory \& Techniques, IEEE Transactions on Antennas \& Propaga- 
tion, IEEE Antennas and Wireless Propagation Letter, Electronic Letters and Microelectronics Journal.

HuanHuan YANG has received the M. Eng. degree in Electronic Science and Technology from the Air Force
Engineering University, Xi' an China, in 2012. His research activity has been focused in polarized reconfigurable antenna He has authored and coauthored more than 30 scientific papers in major journals and international conferences. 